\title{
Effects of TNT Blast on Multistory Structure
}

\author{
Simranjeet Singh', Dushayant Singh Yadav² \\ ${ }^{1}$ Chandigarh University, Gharuan, Chandigarh, India. \\ ${ }^{2}$ Junior engineer, Border road organization, India. \\ Email: Simranjit.cu@gmail.com, dushayant53@gmail.com \\ Published Online: 28 December, 2017 \\ The Author(s) 2017. This article is published with open access at www.chitkara.edu.in/publications
}

\begin{abstract}
For the last few years, rebel activities in addition to related intimidation have been a rising concern throughout the world which not only impacts the human life but also leads to loss of property, both structural impacts and its corporeal integrity. Special prominence has also been agreed to nuisance such as explosion and seismic activity. Different STAAD models generated were analyzed, the results of analysis have been discussed in this section. It contains different amount of TNT and varying standoff distance. Each case has its own maximum and minimum displacement which was found by using STAAD Pro V8i. Two different framed structures were used. In one of the cases, we used simple concrete bare frame having only beams and columns, whereas in the other case we used concrete framed structure with shear wall.
\end{abstract}

\section{INTRODUCTION}

Because of various accidents as well as intentional events, the reaction of different components of structure impacted by blast loading has been a matter of key concern and endured study attempt in previous years. The otherwise predictable structures, predominantly those higher than requisite grades, are generally not designed to withstand explosion or blast loads; though designed at due magnitudes of designing loads are considerably less than that produced by majority of blast, conservative structures and buildings are vulnerable to damages from blasts. Keeping the same in mind, all concerned, such as engineers developers and architects are increasingly concerned about finding solutions to potential blast conditions, in order to guard edifice occupants as as the structures.

Disasters including the militant bombings at the U.S. embassies of Nairobi, Kenya and Dares Salaam, and at Tanzania in year 1998, military barracks at the Khobar Towers of Dhahran, and in Saudi Arabia in year 1996, at the Murrah Federal Building in Oklahoma City in year 1995, and the W.T.C in New York in 1993 have expressed the requirement for a detailed investigation of the performance of columns impacted by blast loads (Kirk, et al., 2005). To
Journal on Today's Ideas Tomorrow's Technologies, Vol. 5, No. 2, 2017 pp. $156-161$

CHITKARA 司 
ensure sufficient prevention adjacent to explosions and blasts, the construction and design of community buildings have received transformed concentration of architects and civil engineers. Though problems arise with these complexities that include time dependent finite deviations, higher strains, and non-linear non elastic behaviour of material, have led to various assumptions, approximations that could simplify such models. Such models span the whole range of sophistication starting with single degree of freedom systems up to programs of general purpose finite element including ANSYS, ABAQUS, and ADINA.

The study and the investigation of blast load on structures began in 1960's. The unit of Army, USA, launch a manual under the title "structures to resist the effects of accidental explosions" in 1959. Its successive edition (TM 5-1300 (1990))(Army, n.d.) has been mostly used by armed forces and civilian organizations while referring for the design of structures in order to prevent the transmission/penetration of detonation and its effects so that safety for personnel and priceless things and equipments could be provided.

Following are the methods accessible for predicting blast effect on structures and buildings i.e.

- Numerical methods

- Empirical/ Analytical methods

- Semi-empirical methods

Numerical methods or the first-principle methods are solely base on mathematical equations which can explain the fundamental laws of physics that govern a given problem. Such principles may consist of conservation of momentum, conservation of energy and conservation of mass. Also, the physical attributes and behaviour of a material is clearly described by the relations of its constitutions. Such models are generally called the computational fluid dynamics (CFD) models

Empirical methods, as is the name, are certainly in correlation with the tentative data. Majority of such approach are confined to a limit of the tentative database that forms its basis. The accurateness of all such empirical equations decreases by the explosion/explosive incident comes closer to the countryside.

The essential element is the load that has been produced from a source of explosion, how it interacts with the given structure and how the structure responds to such a load. A source of explosion may include a gas, a highly explosive material, nuclear substances or dirt materials. The common features of an explosion and a blast wave phenomenon have been presented with reference to a discussion of TNT (trinitrotoluene) equivalency, keeping in regard, the blast scaling laws. The characteristic features of an incident that are overpressure-loading due to an atomic weapon, conventionally high 
Singh, S.

Yadav, D. S.

explosion and unconfined vapours of a cloud explosion have been addressed that follow a description of other blast loading elements that are associated with the flow of air and the process of reflection. Fertice G., has extensively studied the structures and the computations of the impacts of blast loading on superstructures.

\section{MATERIALS AND METHODS}

In this work there are many major concepts were taken place such as: Firstly blast load is taken into consideration, where the blast is a resemblance of TNT explosive. Blast is taken of different load like $500 \mathrm{~kg}, 400 \mathrm{~kg}, 300 \mathrm{~kg}, 200 \mathrm{~kg}$, $100 \mathrm{~kg}$; each load has different intensity on the building. In $500 \mathrm{~kg}$ load, it has maximum value in kilo Newton. Where in $400 \mathrm{~kg}$ value is less as compare to the previous case successively it decrease in further decreasing the load from $300 \mathrm{~kg}$ to $200 \mathrm{~kg}$ and $100 \mathrm{~kg}$. This proportion says the weight of explosive is directly proportioned to the intensity of load on building in kilo Newton.

Secondly, the major factor is standoff distance which equally has a major outcome in pressure face by the building. It is also directly proportional to the pressure as the distance increases where the blast explode the pressure intensity also decreases.

The third factor is a height of building which concludes that columns and nodes at upper stories phase less impact of blast pressure load as compare to columns and nodes at the base of a building.

Lastly, these values are put in Staad pro v8i and analysis is done with help of time history analysis method where blast load is acting on each and every node and in each direction of the structure. Apart from blast load, floor load is also considered on each floor and a dead load is applied to the whole building.

\section{OBSERVATIONS}

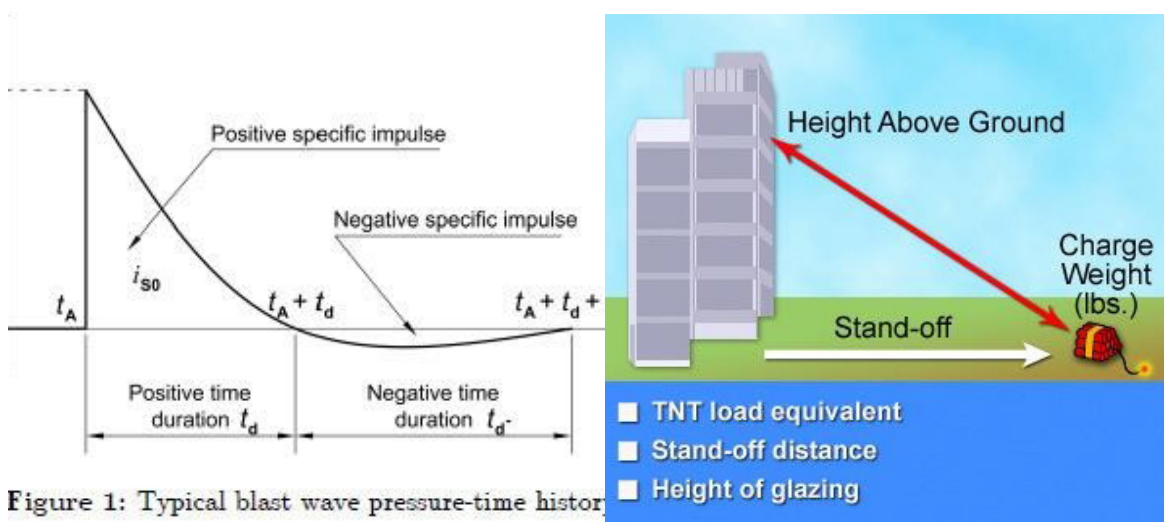




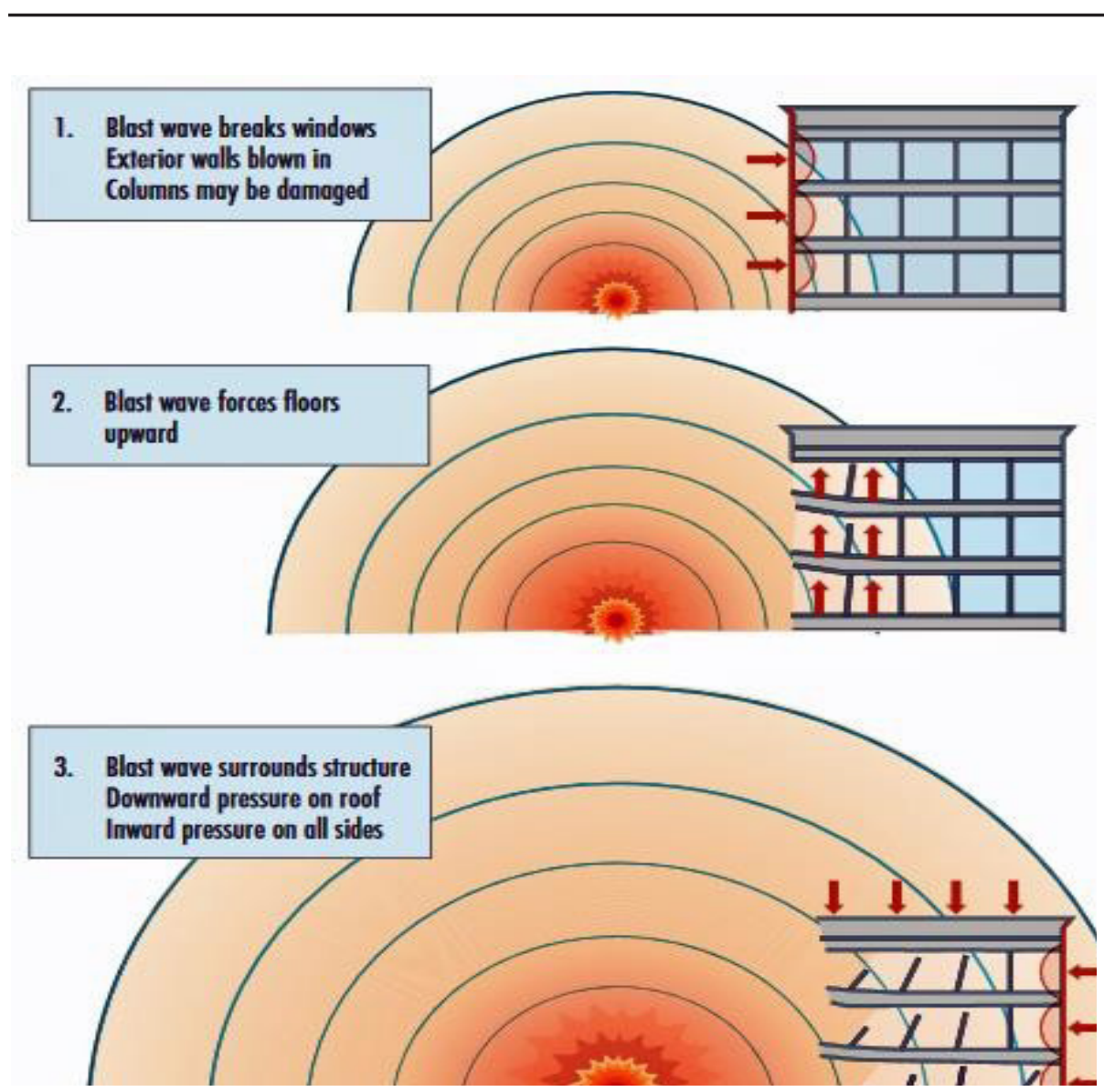

\section{Pressure Chart}

\begin{tabular}{|c|c|c|c|c|c|}
\hline $\begin{array}{c}\text { Stand } \\
\text { Off (ft) }\end{array}$ & $\begin{array}{c}\text { Velocity } \\
\text { (ftmsec) }\end{array}$ & $\begin{array}{c}\text { Time of Arrival } \\
\text { (msec) }\end{array}$ & $\begin{array}{c}\text { Pressure } \\
\text { (PSI) }\end{array}$ & $\begin{array}{c}\text { Impulse } \\
\text { (psi-msec) }\end{array}$ & $\begin{array}{c}\text { Duration } \\
\text { (msec) }\end{array}$ \\
\hline 10 & 5.76 & 1.04 & 3286.61 & 1067.39 & 0.65 \\
\hline 30 & 2.08 & 7.66 & 160.02 & 249.12 & 3.11 \\
\hline 50 & 1.5 & 19.26 & 37.85 & 135.78 & 7.18 \\
\hline 70 & 1.33 & 33.59 & 17.32 & 92.69 & 10.7 \\
\hline 90 & 1.26 & 49.19 & 10.62 & 70.21 & 13.23 \\
\hline 110 & 1.22 & 65.38 & 7.52 & 56.46 & 15.01 \\
\hline 130 & 1.2 & 81.87 & 5.78 & 47.19 & 16.33 \\
\hline 150 & 1.19 & 98.53 & 4.67 & 40.53 & 17.35 \\
\hline
\end{tabular}


Singh, S.

Yadav, D. S.

\section{RESULTS AND CONCLUSIONS}

Different STAAD models generated were analyzed, the results of analysis have been discussed in this section. It contains different amount of TNT and varying standoff distance. Each case has its own maximum and minimum displacement which was found by using STAAD Pro V8i. Two different framed structures were used. In one of the cases, we used simple concrete bare frame having only beams and columns, whereas in the other case we used concrete framed structure with shear wall. Maximum overall displacement in the building was chosen to be the main criteria for the comparisons of results all displacements value is in $\mathrm{mm}$.

It can be observed from literature survey that for the purpose of the estimation of load due to blast or its pressure the empirical approach (Friedlander equation) comes out as an ideal as blast phenomenon does not have a simple nature. Complexity emerges due to the unprecedented charge weight and with change in distance of standoff, the response of material in the influence of different conditions of loading and the events that get triggered after the blast. StaadPro V8i is efficient and easy to operate software for the purpose of designing and simulation of the blast wave formation and the impact loads that link it with the environment of workbench. The simulation of the blast had been carried out with the empirical equations as an equation for the state for explosive materials. The multi storied concrete structure had been subjected to weights of different intensity of blast charge at varying standoff distances for obtaining different parameters of output such as deflection and joint reactions with the help of Staad Pro V8i. A column from the structure was subjected to varying values of charge weight with different combinations of standoff distance for obtaining different parameters as may be total deformation, maximum principal stressor maximum principal strain. The concrete walls were analyzed for obtaining the contours of pressure and the time history analysis plots were obtained to examine its nature and the effects on it.

The observations and conclusions that can be drawn from the present study are, as follows:

1. The blast loads, cause formation of maximum reactions on nodes ostructure leading to the collapse in shear of joints and even the total collapse of structure as well.

2. The structure was analyzed using Staad Pro V8i. The explicit dynamics clearly specify that the effects of an explosion are largely dependent upon, Stand off distance

3. Large deformations were occurred if the quantity of blast weight is more, even for the same value of standoff distance as is clear from the graphs. 
4. Higher stress values were observed for higher values of blast weight in comparison with the lower blast weights as can be seen from the table and graph.

5. The post processing of staadpro $\mathrm{v} 8 \mathrm{i}$ analysis expressed:

\author{
Effects of \\ TNT Blast \\ on Multistory \\ Structure
}

- For columns loaded axially, there exists a critical lateral blast impulse.

- Any blast impulse applied above this value results in the column and concrete structure to failure even before the reach of allowable beam deflection criterion.

6 For higher value of charge weights:

- The fall down of structure comes very fast, as can be seen from the graphs.

- The column fails in half the time for $500 \mathrm{~kg}$ TNT than for $400 \mathrm{~kg}$ TNT, whereas for $500 \mathrm{~kg}$

TNT, it takes approximate one-sixth the time to fail than $300 \mathrm{~kg}$ TNT.

\section{REFERENCES}

1. Draganić, H., \& Sigmund, V. (2012) "Blast Loading on Structures", Tehnički Vjesnik, 19(3), 643-652.

2. G.I. TAILOR(1939). (1939) “The Air Wave Surrounding an Expanding Sphere', (December 1939), PG.292.

3. Marchand, K. A., \& Alfawakhiri, F. (2004) "Blast and Progressive Collapse", Facts for Steel Buildings, 2(2), 1-67.

4. Meghanadh, M., Pradesh, A., Reshma, T., \& Pradesh, A. (2017) "Blast Analysis and Blast Resistant Design of R . C . C Residential Building", 8(3), 761-770.

5. Pandey, A. K., Kumar, R., Paul, D. K., \& Trikha, D. N. (2006) "Non-linear response of reinforced concrete containment structure under blast loading", Nuclear Engineering and Design, 236(9), 993- 1002. https://doi.org/10.1016/j.nucengdes.2005.09.015

6. Safety_Stand_Off_Distances_Card. (n.d.).

7. Shallan, O., Eraky, A., Sakr, T., \& Emad, S. (2014). Response of Building Structures to Blast Effects, 4(2), 167-175.

8. Shope, R. L. (2006). Response of Wide Flange Steel Columns Subjected to Constant Axial Load and Lateral Blast Load. Civil Engineering, Doctor of, 1-417.

9. Unde, A. B., \& Potnis, S. C. (2013) "Blast Analysis of Structures", 2(7), 2120-2126.

10. Vijay, A., \& Subha, K. (2017) "Effect of Longitudinal Reinforcements in Reinforced Concrete Piers Subjected to Blast Loading", 8(11), 73-79.

11. Zhang, R., \& Phillips, B. M. (2016) "Performance and Protection of Base-Isolated Structures under Blast Loading”, Journal of Engineering Mechanics, 142(1), 04015063 1-12. https://doi.org/10.1061/(ASCE)EM.1943-7889

12. J.M. Dewey (1971), "The Properties of Blast Waves Obtained from an analysis of the particle trajectories”, Proc. R. Soc. Lond. A.314, pp. 275-299.

13. Alexander M. Remennikov, (2003) "A review of methods for predicting bomb blast effects on buildings", Journal of Battlefield Technology, vol 6, no 3. pp 155-161 